\title{
Using Doppler ultrasonography on day 34 of pregnancy to predict pregnancy loss in lactating dairy cattle
}

\author{
Dale E. Kelley, ${ }^{*}$ Klibs N. Galvão, † Christopher J. Mortensen, ${ }^{*}$ Carlos A. Risco, $†$ and Alan D. Ealy $\ddagger^{1}$ \\ *Department of Animal Sciences, and \\ †Department of Large Animal Clinical Sciences, University of Florida, Gainesville 32611 \\ ‡Department of Animal and Poultry Science, Virginia Polytechnic Institute and State University, Blacksburg 24061
}

\begin{abstract}
The objective of this experiment was to determine whether uterine or ovarian vascular dynamics could be used to identify cows at risk for pregnancy loss. Our hypothesis was that cows that subsequently lose their pregnancy will have decreased corpus luteal (CL) perfusion, or an increased resistance index (RI; reduced blood flow), or both, at d 34 of pregnancy. Day 34 was chosen because it is a common time for dairy cattle to be checked for pregnancy. This experiment was performed in 2 replicates from November 2011 to April $2012(\mathrm{n}=69)$ and from November 2012 to April 2013 $(\mathrm{n}=53)$. Cows were bred via timed artificial insemination using Ovsynch-56 and checked for pregnancy on d 32 after artificial insemination. At d 34, cows confirmed pregnant were examined via transrectal Doppler ultrasonography. Blood samples collected via coccygeal vein were used to measure circulating plasma progesterone concentrations. Diameter of the corpus luteum and crown-rump length were measured. Color power Doppler ultrasonography was used to determine vascular perfusion to the CL, and RI was measured for the uterine arteries just after branching from the umbilical artery. Records were later examined to identify pregnancy status of cows after reconfirmation. Abortion rate did not differ between replicates (11.6\% in replicate $1,9.4 \%$ in replicate 2). Mean crown-rump length of embryos that were carried to term was greater on $\mathrm{d} 34$ than that in cows that aborted $(14.23 \pm 0.27$ vs. $13.21 \pm 0.53$ $\mathrm{mm})$. Circulating progesterone concentration at $\mathrm{d} 34$ was greater for cows that carried pregnancies to term than for those that aborted $(9.1 \pm 0.7$ vs. $7.5 \pm 1.0$ $\mathrm{ng} / \mathrm{mL})$. The final logistic regression model consisted of crown-rump length, progesterone concentration, and RI of the uterine artery contralateral to pregnancy. Decreased crown-rump length and progesterone concentration tended to be associated with increased odds
\end{abstract}

Received September 2, 2016.

Accepted December 18, 2016.

${ }^{1}$ Corresponding author: ealy@vt.edu ratio for pregnancy loss, whereas CL perfusion and uterine blood flow were not associated with increased odds ratio of pregnancy loss. In conclusion, examining CL perfusion and RI of the uterine arteries on $d 34$ of pregnancy does not offer a method to identify lactating Dairy cattle at risk for pregnancy loss after d 34 .

Key words: dairy cattle, pregnancy loss, Doppler ultrasonography

\section{INTRODUCTION}

Dairy producers face several challenges that affect financial returns, one of which is reproductive efficiency (Meadows et al., 2005). Methods have been developed to maximize the number of cows and heifers bred (Johnson and Funston, 2013; Wiltbank and Pursley, 2014); however, early and late embryonic and fetal losses remain a challenge. An estimated $60 \%$ of pregnancies are lost after conception in lactating dairy cows (Santos et al., 2004), and an estimated $12 \%$ of pregnancies fail after d 42 (Santos et al., 2004). Developing methods to identify cows at risk for pregnancy loss can provide opportunities to develop intervention strategies that will mitigate these losses.

Various indicators of pregnancy status may be used to predict pregnancy loss in cattle. Ultrasound-detected embryonic and fetal abnormalities are strong predictors of impending pregnancy failure in dairy cattle (Gábor et al., 2016). Also, circulating concentrations of pregnancy-associated glycoproteins may be used to predict pregnancy outcomes in cattle (López-Gatius et al., 2007; Thompson et al., 2010). Indicators of corpus luteum (CL) function may also predict pregnancy maintenance or loss in cattle. Size of the CL does not predict pregnancy maintenance or loss, but a positive association exists between the presence of $2 \mathrm{CL}$ and pregnancy maintenance (López-Gatius et al., 2002; Starbuck et al., 2004). Also, circulating progesterone concentration is a predictor of pregnancy loss (Starbuck et al., 2004; López-Gatius et al., 2007). There is a positive correlation between CL blood flow, as evaluated via Doppler ultrasonography, and progesterone 
concentrations in cyclic and pregnant cattle examined up to d 40 of pregnancy (Utt et al., 2009; Herzog et al., 2010). It is not known whether CL blood flow can be used to predict pregnancy outcomes in cattle. However, such an association exists in humans. A positive correlation exists between CL blood perfusion index and circulating progesterone concentrations in women during the first 12 wk of pregnancy (Guerriero et al., 1999), and there is an increase in resistance index (RI) to the CL (i.e., reduced blood perfusion) in women with a threatened miscarriage between 6 and 12 wk of gestation compared with women with a normal pregnancy (Salim et al., 1994).

Resistance index is used in human obstetrics to evaluate pregnancies. It is used for similar purposes in livestock and, especially, large domesticated animals (Ginther, 2007). Differences in RI of the uterine artery ipsilateral to the conceptus pregnancy compared with the contralateral uterine artery are noted in pregnant cattle as early as $60 \mathrm{~d}$ of pregnancy in cows (Bollwein et al., 2002). Vascular changes in the endometrium have been examined using color Doppler ultrasonography, and differences in the amount of perfusion of the uterine endometrium in pregnant heifers compared with nonpregnant heifers are evident as early as d 16 of pregnancy (Silva and Ginther, 2009). There is a paucity of data regarding early changes in uterine blood flow and pregnancy maintenance in cattle, but increased impedance of the uterine artery (i.e., reduced blood flow rate) in women has been associated with recurrent pregnancy loss (Ferreira et al., 2007).

The objective of this project was to discern whether uterine or ovarian vascular dynamics would identify cows at risk for pregnancy loss. The hypothesis was that cows that abort after d 34 would have decreased CL perfusion or increased RI (suggestive of decreased uterine blood flow), or both, at d 34 of pregnancy.

\section{MATERIALS AND METHODS}

\section{Experimental Design}

This experiment was performed in 2 replicates from November 2011 to April $2012(\mathrm{n}=69)$ and from November 2012 to April $2013(\mathrm{n}=53)$ at the University of Florida Dairy Unit (Hague). First-service lactating Holstein cows ( 2 to $12 \mathrm{yr}$ of age, mean $=2.2 \mathrm{yr}$ ) received timed AI using the Ovsynch-56 protocol. Pregnancy was diagnosed at d 32 post-AI by transrectal ultrasound. The presence of an embryo with a heartbeat was the criterion used to determine pregnancy. Cows diagnosed pregnant were re-examined by transrectal palpation of uterine contents at 46, 75, and $210 \mathrm{~d}$ of gestation to reconfirm pregnancy and to identify abortion. Records were later examined to identify cows that aborted and approximately when the abortion occurred, as well as DIM, milk yield, BCS, and BW.

\section{Ultrasonography}

At d 34, cows confirmed pregnant were examined via transrectal Doppler ultrasonography (Micromaxx; Sonosite, Bothell, WA) using a 5- to $10-\mathrm{MHz}$ broadband 52mm linear array (Micromaxx; Sonosite). Crown-rump length and diameter (average of height and width) of the CL were measured. Images of vascular perfusion to the CL were completed with color power Doppler ultrasonography at the maximum diameter of the CL, with the probe oriented from the caudal to cranial ovarian poles and recorded to digital video. The percent of the CL being perfused with blood was measured using digital videos by comparing the CL area containing blood flow versus the total CL area, as previously described by Kelley et al. (2009). The RI was measured for the uterine artery ipsilateral and contralateral to the uterine horn containing a pregnancy (Bollwein et al., 2000).

\section{Blood Collection and Progesterone Analysis}

Blood samples were collected on d 34 via coccygeal venipuncture into blood collection tubes containing EDTA (Vacutainer, $10 \mathrm{~mL}$; Becton, Dickinson and Company, Franklin Lakes, NJ). Samples were placed on ice until plasma was isolated by centrifugation $(5,000$ $\times g$ for 15 min at $4^{\circ} \mathrm{C}$ ). Plasma was frozen at $-20^{\circ} \mathrm{C}$ until progesterone concentration was determined using Coat-A-Count solid-phase ${ }^{125}$ RIA kits (DPC Diagnostic Products Inc., Los Angeles, CA; Cooke et al., 2009). Intra- and interassay coefficients of variation were $2.73 \%$ and $3.95 \%$, respectively, and assay sensitivity was $0.1 \mathrm{ng} / \mathrm{mL}$.

\section{Statistical Analyses}

Abortion rates between replicates were compared using the SAS FREQ (version 9.4; SAS Institute Inc., Cary, NC) procedure involving a Chi-squared statistic. Continuous data were normally distributed as assessed by a Kolmogorov-Smirnov test. Initially, RI, CL perfusion, CL diameter, crown-rump length, and plasma progesterone concentrations were analyzed as dependent variables using the SAS MIXED procedure. Independent variables used in the model were DIM, milk yield, parity (primiparous vs. multiparous), BCS, BW, pregnancy loss, and pregnancy loss $\times$ parity. Replicate was modeled as a covariate. A backward elimination model was used with eligibility to remain in the model set at $P=0.15$. 
KELLEY ET AL.

Table 1. Odds ratio estimated and $95 \%$ CI for cows that lost a pregnancy or remained pregnant to term

\begin{tabular}{lccc}
\hline Dependent variable $^{1}$ & Pregnancy lost & Term & $P_{\text {-value }}^{2}$ \\
\hline CL perfusion, \% & $10.8 \pm 4.0$ & $15.3 \pm 2.7$ & 0.18 \\
Crown-rump length, mm & $13.21 \pm 0.53$ & $14.23 \pm 0.27$ & 0.05 \\
Progesterone, ng/mL & $7.5 \pm 1.0$ & $9.1 \pm 0.7$ & 0.03 \\
RI: gravid horn & $0.90 \pm 0.05$ & $0.89 \pm 0.02$ & 0.79 \\
RI: nongravid horn & $1.04 \pm 0.05$ & $1.01 \pm 0.02$ & 0.44 \\
\hline
\end{tabular}

${ }^{1} \mathrm{CL}=$ corpus luteum; $\mathrm{RI}=$ resistance index. CL perfusion: percentage of total cross-sectional area perfused with blood.

${ }^{2}$ Mixed model regression with a backward selection procedure and $P$-values for dependent variables.

Abortion was also modeled as a dependent variable using SAS LOGISTIC procedure with replicate, DIM, milk yield, parity, BCS, RI, CL perfusion, CL diameter, crown-rump length, and plasma progesterone concentrations as independent variables. A backward elimination model was used with eligibility to remain in the model set at $P=0.15$. Odds ratios were then calculated and a receiver operator characteristic curve was plotted for those variables in the final model. Data analyzed as a mixed model were presented as least squares means \pm standard errors of the mean, and data analyzed via logistic regression were presented as odds ratio (95\% CI).

\section{RESULTS}

Pregnancy loss after d 34 did not differ between the first and second replicate (11.6 and 9.4\%, respectively). The combined abortion rate after d 34 was $10.7 \%$. Of the cows experiencing pregnancy loss, 6 aborted by d 46, 5 between d 56 and 74, and 2 between d 136 and 144. Six of these cows were primiparous and 7 were multiparous. No causes for abortions were determined.

\section{Mixed Models}

The mean crown-rump length in cows that remained pregnant was less in cows that lost a pregnancy $(P=$ 0.05; Table 1) compared with those that maintained a pregnancy to term. None of the other variables in the initial model had a significant effect. Circulating progesterone concentrations were also affected by pregnancy outcomes, with cows that remained pregnant to term having greater progesterone concentrations than those that aborted after d 34 (Table 1). In addition, DIM $(P=0.01)$ and milk yield $(P=0.05)$ affected progesterone concentrations.

None of the variables modeled had a significant effect on CL diameter. We detected a difference in mean CL perfusion $(P=0.04)$ between primiparous $(12.5 \pm$ $2.8 \%)$ and multiparous $(16.7 \pm 2.7 \%)$ cows, but no difference in CL perfusion between cows that remained pregnant or lost their pregnancy. None of the variables in the model had an effect on RI of the uterine artery contralateral to the pregnancy. Both DIM and BW ( $P$ $\leq 0.05)$ affected RI of the uterine artery ipsilateral to pregnancy. We detected a tendency $(P=0.07)$ for parity to influence RI, with primiparous cows having a mean RI of $0.93 \pm 0.03$ and multiparous cows having a mean RI of $0.86 \pm 0.02$.

\section{Logistic Regression Model}

Using a backward elimination model, crown-rump length $(P=0.07)$, plasma progesterone concentrations $(P=0.09)$, and RI of the uterine artery contralateral to the pregnancy $(P=0.11)$ remained in the final model (Table 2). The area under the curve of the receiver operator characteristic curve of the final model was 0.78.

\section{DISCUSSION}

The ability to identify cows at risk for pregnancy loss can provide opportunities to create intervention strategies that mitigate these losses. A correlation between CL blood flow and progesterone concentrations

Table 2. Odds ratio estimates and 95\% CI for maintaining pregnancy to term for variables that remained in the logistic regression model after a backward elimination procedure

\begin{tabular}{|c|c|c|c|c|}
\hline Variable $^{1}$ & Unit & Odds ratio & $95 \% \mathrm{CI}^{2}$ & $P$-value \\
\hline Crown-rump length & $1.00 \mathrm{~mm}$ & 1.496 & $0.986-2.370$ & 0.07 \\
\hline Progesterone & $1.00 \mathrm{ng} / \mathrm{mL}$ & 1.324 & $0.994-1.911$ & 0.09 \\
\hline RI: uterine artery contralateral to pregnancy & 0.10 & 1.463 & $0.910-2.353$ & 0.11 \\
\hline
\end{tabular}

\footnotetext{
${ }^{1} \mathrm{RI}=$ resistance index.

${ }^{2}$ The $95 \%$ CI was determined by modeling the probability of abortion rather than probability of maintaining a pregnancy to term.
} 
in cattle has been determined (Utt at al., 2009; Herzog et al., 2010). Also, reductions in serum progesterone concentrations are associated with an increased risk of pregnancy loss in cattle (Moore et al., 2005). Therefore, examining CL perfusion may provide a real-time estimation of CL function and identify the risk of pregnancy loss. Additionally, RI of the uterine arteries was examined. An increase in blood flow to the uterine horn bearing the conceptus occurs as early as d 25 of pregnancy (Ford et al., 1979), and an increase in CL perfusion occurs as early as d 30 (Melton et al., 1951; Ford, 1982). This raises the question and possibility of examining uterine blood flow in early pregnancy to identify cows at risk for pregnancy loss.

In this study, perfusion of the CL was not predictive of future abortion status. In crossbred beef cattle, CL perfusion is an effective indicator of CL function but a poor predictor of pregnancy status on d 17, 19, and 21 (Utt et al., 2009). Siqueira et al. (2013) found that CL perfusion on d 20 was a good predictor of pregnancy status in beef cattle (sensitivity of $99 \%$, specificity of $53.7 \%$ ), likely because it can predict CL maintenance versus regression. Several conceptus and endometrial factors may facilitate these changes in uterine blood flow. One notable vasodilator is prostaglandin $\mathrm{E}_{2}$ $\left(\mathrm{PGE}_{2}\right)$. Measurable $\mathrm{PGE}_{2}$ exists in bovine conceptuses at d 11 to 18 (Wilson et al., 1992), and this factor plays a role in CL maintenance (Christenson et al., 1994) and progesterone secretion (Kimball and Lauderdale, 1975).

In the present study, cows that aborted had decreased plasma progesterone concentrations at $\mathrm{d} 34$. The resulting risk of pregnancy loss tended to be associated with reduced plasma progesterone concentrations. Associations between circulating progesterone and pregnancy outcomes have been made at various stages of pregnancy. It is well known that a positive association exists between circulating progesterone and pregnancy success between d 5 and 7 in cattle (Mann and Lamming, 1999, 2001; Stronge et al., 2005). Circulating progesterone can also predict early and late embryonic losses. Moore et al. (2005) found that serum progesterone concentrations at d 21 to 25 were lower in cows that lost their conceptus between $\mathrm{d} 24$ and 28. This indicator also can be used to monitor fetal losses. In pregnant Holstein cows, reduced progesterone at wk 5 is associated with greater pregnancy losses between wk 5 and 9 (Starbuck et al., 2004). Also, cows with additional CL were 8 times less likely to experience pregnancy loss between d 38 and 90 (López-Gatius et al., 2002). Several studies have examined the induction of multiple CL with human chorionic gonadotropin and the effect on pregnancy rates. A meta-analysis by Nascimento et al. (2013) found a 3 percentage point increase in pregnancy rates in cows with induction of multiple CL.
Further examination of the data demonstrated that multiple CL improve pregnancy rates in primiparous but not multiparous cows (Nascimento et al., 2013). Although these studies did not evaluate pregnancy loss, they raised the question of whether induction of multiple CL may provide some benefit to maintenance of pregnancy or alter the risk of pregnancy loss.

Since the 1980s, Doppler ultrasonography has become the method of choice to monitor pregnancies in women, and especially high-risk pregnancies (Bower et al., 1993a,b). Doppler ultrasonography has also gained popularity as a research tool in cattle. A progressive decrease in RI (i.e., increased blood flow) occurs as pregnancy progresses (Bollwein et al., 2002). There is a lack of information relating RI with late embryonic and fetal pregnancy failures in cattle. Correlations between uterine artery RI and pregnancy are equivocal in women (Kurjak et al., 1994; Jaffe et al., 1995; Kurjak and Kuspesic, 1997). The present study failed to detect a difference associated with uterine blood flow at d 34 on pregnancy loss. The most likely possibilities for this outcome are that d 34 is too early to predict failures or that blood flow measurements must be taken closer to the actual time of pregnancy failure to detect alterations in uterine blood flow.

The present study supports the idea that a reduction in crown-rump length may be associated with pregnancy loss after d 34. Cows that aborted had conceptuses with reduced crown-rump length on d 34 compared with cows that carried a pregnancy. Also, these cows tended to have an increased odds ratio for pregnancy loss after $\mathrm{d} 34$. This was consistent with other work in cloned fetuses, where pregnancies that aborted before d 90 of pregnancy had a reduced crown-rump length compared with those that survived to term (Hill et al., 2000; Chavatte-Palmer et al., 2006).

It is noteworthy that primiparous cows had reduced CL perfusion compared with multiparous cows and tended to have an increase in RI compared with multiparous cows. Additionally, a tendency was noted for RI of the uterine artery ipsilateral to pregnancy to be elevated in primiparous compared with multiparous cows. These outcomes were likely related to the diameter of the uterine artery in primiparous versus multiparous cows. Heifers have a smaller-diameter uterine artery compared with cows (Yamauchi and Sasaki, 1968), and maiden mares consistently had smaller diameter of both uterine arteries compared with multiparous mares (Klewitz et al., 2015). Whether the diameter of the uterine artery in primiparous cows is less than that of multiparous cows requires further investigation.

In this study, we performed the Doppler examination at a single time point. This time was chosen so that blood flow, embryonic and progesterone measurements 
could be completed before late embryonic and fetal losses occurred. The small size of the embryo at d 34 might have prevented a more accurate measurement of embryo size. Ideally, Doppler examinations should take place close to when pregnancy loss occurs (e.g., day before loss of embryonic heartbeat). Unfortunately, this was not feasible. Completing measurements again (e.g., 7 to $14 \mathrm{~d}$ later) may have provided more definitive information about pregnancy outcomes. Likewise, completing CL perfusion and RI indices at multiple times would likely have improved the power for predicting pregnancy losses, especially given the animal numbers used in this work. Completing these Doppler assessments earlier in pregnancy (e.g., d 28) might be informative. Earlier dates may be able to capture pregnancy-dependent CL perfusion and RI changes as they are beginning.

\section{CONCLUSIONS}

This study examined the association of CL perfusion and uterine blood flow with pregnancy loss in cattle. No difference was found in CL perfusion or RI in the uterine arteries ipsilateral or contralateral to the uterine horn containing a pregnancy on d 34. Crown-rump length and progesterone concentrations were reduced in cows that subsequently lost their pregnancy. Crownrump length, progesterone concentrations, and RI of the uterine artery contralateral to a pregnancy remained in the logistic regression model; however, RI was not significant. In conclusion, examining CL perfusion and $\mathrm{RI}$ of the uterine arteries on d 34 of pregnancy does not offer a highly predictive method of identify lactating dairy cattle at risk for pregnancy loss after d 34 .

\section{ACKNOWLEDGMENTS}

This work was supported by the Southeast Milk Incorporated Dairy Research and Education Program. We thank Paula M. Mercadante, Steven Bingert, and Eric Diepersloot (University of Florida Dairy Research Unit) for their assistance.

\section{REFERENCES}

Bollwein, H., U. Baumgartner, and R. Stolla. 2002. Transrectal Doppler ultrasonography of uterine blood flow in cows during pregnancy. Theriogenology 57:2053-2061.

Bollwein, H., H. H. D. Meyer, J. Maierl, F. Weber, U. Baumgartner, and R. Stolla. 2000. Transrectal Doppler sonography of uterine blood flow in cows during the estrous cycle. Theriogenology 53:1541-1552.

Bower, S., S. Bewley, and S. Campbell. 1993a. Improved prediction of pre-eclampsia by two-stage screening of uterine arteries using the early diastolic notch and color Doppler imaging. Obstet. Gynecol. 82:78-83.
Bower, S., K. Schuchter, and S. Campbell. 1993b. Doppler ultrasound screening as part of routine antenatal scanning: Prediction of preeclampsia and intrauterine growth retardation. Br. J. Obstet. Gynaecol. 100:989-994.

Chavatte-Palmer, P., N. de Sousa, P. Laigre, S. Camous, A. A. Ponter, J. F. Beckers, and Y. Heyman. 2006. Ultrasound fetal measurements and pregnancy associated glycoprotein secretion in early pregnancy in cattle recipients carrying somatic clones. Theriogenology 66:829-840.

Christenson, L. K., L. H. Anderson, S. P. Ford, and D. B. Farley. 1994. Luteal maintenance during early pregnancy in the pig: Role for prostaglandin $\mathrm{E}_{2}$. Prostaglandins 47:61-75.

Cooke, R. F., J. D. Arthington, B. R. Austin, and J. V. Yelich. 2009. Effects of acclimation to handling on performance, reproductive, and physiological responses of Brahman-Crossbred heifer. J. Anim. Sci. 87:3403-3412.

Ferreira, A. M., C. R. Pires, A. F. Moron, E. Araujo Jùnior, E. Traina, and R. Mattar. 2007. Doppler assessment of uterine blood flow in recurrent pregnancy loss. Int. J. Gynaecol. Obstet. 98:115-119.

Ford, S. P. 1982. Control of uterine and ovarian blood flow throughout the estrous cycle and pregnancy of ewes, sows and cows. J. Anim. Sci. 55(Suppl. 2):32-42.

Ford, S. P., J. R. Chenault, and S. E. Echternkamp. 1979. Uterine blood flow of cows during the oestrous cycle and early pregnancy: Effect of the conceptus on the uterine blood supply. J. Reprod. Fertil. 56:53-62.

Gábor, G., J. P. Kastelic, Z. Abonyi-Tóth, P. Gábor, T. Endródi, and O. G. Balogh. 2016. Pregnancy loss in dairy cattle: Relationships of ultrasound, blood pregnancy-specific protein B, progesterone and production variables. Reprod. Domest. Anim. 51:467-473.

Ginther, O. J. 2007. Ultrasonic imaging and animal reproduction: Color-Doppler ultrasonography. Equiservices Publishing, Cross Plains, WI.

Guerriero, S., S. Ajossa, M. P. Lai, A. Risalvato, M. Paoletti, and G. B. Melis. 1999. Clinical application of colour Doppler energy imaging in the female reproductive tract and pregnancy. Hum. Reprod. Update 5:515-529.

Herzog, K., M. Brockhan-Lüdeman, M. Kaske, N. Beindorff, V. Paul, H. Nieman, and H. Bollwein. 2010. Luteal blood flow is a more appropriate indicator for luteal function during the bovine estrous cycle than luteal size. Theriogenology 73:691-697.

Hill, J. R., R. C. Burghardt, K. Jones, C. R. Long, C. R. Looney, T. Shin, T. E. Spencer, J. A. Thompson, Q. A. Winger, and M. E. Westhusin. 2000. Evidence for placental abnormality as the major cause of mortality in first-trimester somatic cell cloned bovine fetuses. Biol. Reprod. 63:1787-1794.

Jaffe, R., A. Dorgan, and J. S. Abramowicz. 1995. Color Doppler imaging of the uteroplacental circulation in the first trimester: Value in predicting pregnancy failure or complication. AJR Am. J. Roentgenol. 164:1255-1258.

Johnson, S. K., and R. N. Funston. 2013. Postbreeding heifer management. Vet. Clin. North Am. Food Anim. Pract. 29:627-641.

Kelley, D. E., C. J. Mortensen, J. L. Fain, and J. R. Gibbons. 2009. Vascular dynamics of the corpus luteum as it relates to diameter and progesterone concentrations in beef cattle. Biol. Reprod. 81(Suppl. 1):582. (Abstr.)

Kimball, F. A., and J. W. Lauderdale. 1975. Prostaglandin El and F2a specific binding in bovine corpora lutea: Comparison with luteolytic effects. Prostaglandins 10:313-331.

Klewitz, J., C. Struebing, K. Rohn, A. Goergens, G. Martinsson, F. Orgies, J. Probst, F. Hollinshead, H. Bollweins, and H. Sieme. 2015. Effects of age, parity, and pregnancy abnormalities on foal birth weight and uterine blood flow in the mare. Theriogenology 83:721-729.

Kurjak, A., and S. Kuspesic. 1997. Doppler assessment of the intervillous blood flow in normal and abnormal early pregnancy. Obstet. Gynecol. 89:252-256.

Kurjak, A., I. Zalud, M. Predanic, and S. Kuspesic. 1994. Transvaginal color and pulsed Doppler study of uterine blood flow in the first and second trimesters of pregnancy: Normal versus abnormal. J. Ultrasound Med. 13:43-47. 
López-Gatius, F., R. H. Hunter, J. M. Garbayo, P. Santolaria, J. Yániz, B. Serrano, N. M. de Sousa, and J. F. Beckers. 2007. Plasma concentrations of pregnancy-associated glycoprotein-1 (PAG1) in high producing dairy cows suffering early fetal loss during the warm season. Theriogenology 67:1324-1330.

López-Gatius, F., P. Santolaria, J. Yàniz, J. Rutlant, and M. LópezBèjar. 2002. Factors affecting pregnancy loss from gestation Day 38 to 90 in lactating dairy cows from a single herd. Theriogenology $57: 1251-1261$.

Mann, G. E., and G. E. Lamming. 1999. The influence of progesterone during early pregnancy in cattle. Reprod. Domest. Anim. $34: 269-274$.

Mann, G. E., and G. E. Lamming. 2001. Relationship between maternal endocrine environment, early embryo development and inhibition of the luteolytic mechanism in cows. Reproduction 121:175180.

Meadows, C., P. J. Raala-Schultz, and G. S. Frazer. 2005. A spreadsheet-based model demonstrating the nonuniform economic effects of varying reproductive performance in Ohio dairy herds. J. Dairy Sci. 88:1244-1254.

Melton, A. A., R. O. Berry, and O. D. Butler. 1951. The interval between the time of ovulation and attachment of the bovine embryo. J. Anim. Sci. 10:993-1005.

Moore, D. A., M. W. Overton, R. C. Chebel, M. L. Truscott, and R. H. Bondurant. 2005. Evaluation of factors that affect embryonic loss in Dairy cattle. J. Am. Vet. Med. Assoc. 226:1112-1118.

Nascimento, A. B., R. W. Bender, A. H. Souza, H. Ayres, R. R. Araujo, J. N. Guenther, R. Sartori, and M. C. Wiltbank. 2013. Effect of treatment with human chorionic gonadotropin on day 5 after timed artificial insemination on fertility of lactating dairy cows. J. Dairy Sci. 96:2873-2882.

Salim, A., I. Zalud, G. Farmakides, H. Schulman, A. Kurjak, and V. Latin. 1994. Corpus luteum blood flow in normal and abnormal early pregnancy: evaluation with transvaginal color and pulsed Doppler sonography. J. Ultrasound Med. 13:971-975.

Santos, J. E. P., W. W. Thatcher, R. C. Chebel, R. L. A. Cerri, and K. N. Galvão. 2004. The effect of embryonic death rates in cattle on the efficacy of estrus synchronization programs. Anim. Reprod. Sci. 82-83:513-535.

Silva, L. A., and O. J. Ginther. 2009. Local effects of the conceptus on uterine perfusion during early pregnancy in heifers. Reproduction 139:453-463.

Siqueira, L. G. B., V. S. Areas, A. M. Ghetti, J. F. Fonseca, M. P. Palhao, C. A. C. Fernandes, and J. H. M. Viana. 2013. Color Doppler flow imaging for the early detection of nonpregnant cattle at 20 days after timed artificial insemination. J. Dairy Sci. 96:6461-6472.

Starbuck, M. J., R. A. Dailey, and E. K. Inskeep. 2004. Factors affecting retention of early pregnancy in Dairy cattle. Anim. Reprod. Sci. 84:27-39.

Stronge, A. J. H., J. M. Sreenan, M. G. Diskin, J. F. Mee, D. A. Kenny, and D. G. Morris. 2005. Post-insemination milk progesterone concentration and embryo survival in dairy cows. Theriogenology 64:1212-1224.

Thompson, I. M., R. L. Cerri, I. H. Kim, J. A. Green, J. E. Santos, and W. W. Thatcher. 2010. Effects of resynchronization programs on pregnancy per artificial insemination, progesterone, and pregnancy-associated glycoproteins in plasma of lactating dairy cows. J. Dairy Sci. 93:4006-4018.

Utt, M. D., G. L. Johnson III, and W. E. Beal. 2009. The evaluation of corpus luteum blood flow using color-flow Doppler ultrasound for early pregnancy diagnosis in bovine embryo recipients. Theriogenology 71:707-715.

Wilson, J. M., D. D. Zalesky, C. R. Looney, K. R. Bondioli, and R. R. Magness. 1992. Hormone secretion by preimplantation embryos in a dynamic in vitro culture system. Biol. Reprod. 46:295-300.

Wiltbank, M. C., and J. R. Pursley. 2014. The cow as an induced ovulatory: Timed AI after synchronization of ovulation. Theriogenology 81:170-185.

Yamauchi, S., and F. Sasaki. 1968. Studies on the vascular supply to the uterus of the cow: Morphological studies of arteries in the broad ligament. Bull. Univ. Osaka Prefect. B Agric. Biol. 20:33-47. 